\title{
A Study on the Application of the Ethnography in Developing Intercultural Communication Competence (ICC)*
}

\author{
WANG Rui-ying \\ South China Business College (SCBC), Guangdong University of Foreign Studies (GDUFS), Guangdong, China
}

\begin{abstract}
This article focused on the application of ethnography as a qualitative study in developing non-English majors' intercultural communication competence (ICC). The PEER model guided student researchers through the interdependent phrases of preparing, engaging, evaluating and reflecting in the research procedure. In addition, the four components of Byram’s ICC model, namely, knowledge, skills, attitudes, and critical awareness, were used to assess students' ICC development.
\end{abstract}

Keywords: ethnography, ICC, knowledge, skills, attitudes, critical awareness

\section{Introduction}

With the development of foreign language education, its focus has been transformed from language knowledge skills, communicative skill, to intercultural communication competence (ICC). ICC has been considered as "the ultimate goal of foreign language education" (Zhao \& Kan, 2016). Over the past 20 years, there has been a dramatic increase in the study of ICC. Teachers and experts of intercultural communication (IC) have been designing, developing, and applying various methods for/into improving students' ICC, ranging from lectures, critical incidents, culture capsules, culture clusters, to simulation games (Zhang, 2007). Among all these methods, the ethnographic technique has constantly been proposed and used as an effective means of improving ICC (Zhang, 2007). Byram (2014) even explicitly stated that "culture teaching is moving toward an ethnographic perspective".

Being different from the traditional ethnography which requires long-term actual participation in and observation of the target culture, the "pragmatic ethnography" proposed by Danmen in 1987 can be accessible to most people and workable for IC classroom teaching as long as there are sources from the target culture which can be observed and people from the target culture who can be the informants (Zhang, 2007). The aim of this paper is to provide insights into the effectiveness and limitations in applying the ethnographic approach for non-English majors' development of ICC.

\footnotetext{
* Acknowledgement: This research is sponsored by the key college project A Study on the Application of the Ethnography in developing intercultural communication competence (ICC) as a subproject of the Key Program of the English Language and Literature of Guangdong Province, 2016; by Guangdong provincial project A Study of Intercultural College English Teaching Based on Constructivism under the Background of the Belt and Road (B \& R) (Grant No. 2017GXJK245); and by the university project An Action Research of the College English Teaching Model Based on Intercultural Perspective under the Background of B \& R in SCBC (Grant No. 2017JG03).

WANG Rui-ying, master, lecturer, South China Business College (SCBC), Guangdong University of Foreign Studies (GDUFS), Guangdong, China.
} 


\section{Literature Review}

\section{Intercultural Communication Competence (ICC)}

There has been little consensus as for the definition of ICC. Numerous scholars have attempted to explore the key concepts of ICC (Fu, 2017). Among various definitions of ICC, however, there are some similar concepts, such as "effectively" and "appropriately". This study is an open-ended exploration for the effects of ethnographic approach on non-English major's ICC development, ICC will be defined in this thesis as "the ability to communicate effectively and appropriately based on one's intercultural knowledge, skills, attitudes, and critical cultural awareness” (Byram, 2014).

Different ICC models have been devised in recent years, the most wildly-known and influential are Byram's (2014) model of intercultural communicative competence, and J. Bennett and M. Bennett's (2004) intercultural development continuum. Byram's model (see Table 1) will be used as frame of reference for assessment of participants' ICC developments in this study for its clarity and accessibility.

Table 1

Factors in IC

\begin{tabular}{|c|c|c|}
\hline & $\begin{array}{c}\text { Skills } \\
\text { Interpret and relate }\end{array}$ & \\
\hline $\begin{array}{c}\text { Knowledge } \\
\text { Of self and other; } \\
\text { Of interaction; } \\
\text { Individual and societal }\end{array}$ & $\begin{array}{c}\text { Education } \\
\text { Political education } \\
\text { Critical culture awareness }\end{array}$ & $\begin{array}{c}\text { Attitudes } \\
\text { Relativising self } \\
\text { Valuing other }\end{array}$ \\
\hline & $\begin{array}{c}\text { Skills } \\
\text { Discover and / or interact }\end{array}$ & \\
\hline
\end{tabular}

Source: Byram (2014).

In Byram's ICC model, four factors are taken into account while assessing students' development of ICC, namely, knowledge, skills, attitudes, and critical awareness. Intercultural knowledge means "of social groups and their products and practices one's own and in one's 'interlocutor's' country, of the general processes of societal and individual interaction” (Byram, 2014). Skills include the skills of interpreting, relating, discovering, and interaction. Attitudes refer to "curiosity and openness, readiness to suspend disbelief and judgment with respect to other's meaning, beliefs, and behaviors.... A willingness to suspend one's one beliefs, meanings, and behaviors, and to analyze them from the viewpoint of the others with whom one is engaging” (Byram, 2014). Intercultural speakers also need critical awareness to "evaluate critically and on the basis of explicit criteria perspectives, practices and products in one's own and other cultures and countries” (Byram, 2014). These elements mentioned above will serve as major guidelines in later data analysis process to assess students’ ICC.

\section{Studies on Application of the Ethnographic Approach in ICC Development}

Ethnography was rooted in anthropology. Traditionally, ethnography requires long-term actual participation and observation of target culture, as it is stated as "field work". Nevertheless, the "field work" can be in various forms. The student researchers can interact with the people of their target culture through watching video clips or face-to-face interviews, through interviews via the telecommunication devices, such as the Skype, emails, video-conferencing, Wechat, or chat rooms (Lu, 2012). This kind of pragmatic ethnography proposed by Damen (1987) overcame the spatial limitations facing most foreign language learners, expands intercultural learning 
beyond the classroom, and easily applicable to language teaching.

From the principles of ethnography, two major characteristics can be derived. Firstly, researchers are required to be sensitive observers in ethnography. Researchers need to be more cautious in their encounters with and studies of a foreign culture, and listen actively in culture interview (Robinson-Stuart \& Nocon, 1996). Secondly, ethnography is a process-oriented research method with "thick description” (Lu, 2012). With a detailed description of some background information and the process of the study, readers can understand the event itself as well as identify the true meaning by referring to its context.

Due to the characteristics of ethnography, researchers have shown an increased interest in employing ethnography as a good way to deepen learners' understanding of both their own culture and the target culture. Robinson-Stuart and Nocon (1996) conducted an empirical study to investigate the effectiveness of ethnographic interview techniques in breaking down cultural barriers facilitating communications and cultivating positive attitudes between language students and target language speakers (Robinson-Stuart \& Nocon, 1996). Jackson (2006) focused on the ethnography in an experiential language and cultural immersion program for Hong Kong English majors, revealing that this approach encouraged them to become more conscious of the uniqueness of their own culture and develop an understanding and appreciation of other worldviews (Jackson, 2006). Du (2008) did an examination of the ethnographic interview approach in a Chinese as a foreign language classroom to find out that it could enhance students' intercultural awareness and competence as well as increase students' intercultural sensitivity ( $\mathrm{Du}, 2008$ ). Lu (2012) used the learners-as-ethnographers approach to enhance intercultural learning among American college students learning Chinese as a foreign language (Lu, 2012). Holmes and O'Neil (2012) developed a preparing, engaging, evaluating, and reflecting (PEER) model to develop and evaluate ICC by using an ethnographic approach (Holmes \& O’Neil, 2012). Fu (2017) explored the effects of ethnographic approach on students' ICC development in a non-language teaching context and in an online environment (Fu, 2017).

So far, however, there has been little discussion about how Chinese learners use ethnography in domestic setting to improve their ICC in English learning classes, how they view the target culture and their own, and to what extent and in what way the pragmatic ethnography can facilitate intercultural learning. This study seeks to address these questions.

\section{Research Design}

\section{Setting and Participants}

With the highly developed communication technologies, video clips from TV series, and movies could be easily obtained as cultural observation, which realistically portrays life as well as other culture aspects in the target culture, such as Family Album: USA, Friends, Guasha, The Joy Luck Club, and Pushing Hands, etc. A target culture informant online for language learners is also available. In addition, there are a number of foreign teachers and exchange students in the college in which the author works. All the non-English majors obtain an English speaking class given by foreign teachers. Foreign teachers also organize a series of extra-curriculum activities which are accessible to all the students of the college, including English talk, English corner, Time Space, Reading Club, and Chitchat with foreign teachers.

Forty-five sophomore students studying the course of IC given by the author were recruited for this study 
with their consent. There are 18 males and 36 females aged 19-20.

\section{Research Procedure}

A one-semester-long (16 weeks) project (see Table 2) was designed containing four interdependent and interconnected steps based on the ethnographic PEER model developed by Holmes and O’Neil (2012). Forty-five students were divided into six groups to explore six aspects of intercultural learning.

Table 2

Time Arrangement and Tasks

\begin{tabular}{lll}
\hline Week No. & Stage & Tasks \\
\hline W1-W3 & Preparing & 1. Ethnography and its interview skills; 2. Grouping; 3. Observation, generalization, and discussion. \\
W4-W8 & Engaging & 1. Culture interview(s); 2. Interview records; 3. Ethnographic interview skills check. \\
W9-10 & Evaluating & 1. Group discussion; 2. Group presentation. \\
W11-16 & Reflecting & 1. Reflection; 2. Individual ethnographic report writing; 3. Group learning portfolio. \\
\hline
\end{tabular}

Preparing. Firstly, students were taught some basic information about ethnography and they practiced ethnographic interview techniques in class as well. Lu (2012) recommended a list of practical guidelines for ethnographic interview techniques: start with open or grand-tour questions; allow time for interviewee's responses; listen interactively; focus on the speaker; ask for clarification when necessary; rephrase the questions when necessary; be patient when exploring the information beneath the surface; show appreciation. Secondly, students were divided into six groups and assigned to choose the topic related to what we were learning for research, and observe and generalize related aspect of American culture and Chinese culture by searching information from the internet or watching video clips. Students were guided to discuss with their group members about what they observed and generalized.

Engaging. In order to check their generalization of their research topic, students were supposed to have at least one face to face culture interview with an informant or an interview via the telecommunication devices, such as the Skype, emails, and Wechat. They were required to record the interview or take notes whether the ethnographic interview skills were applied should be checked after the interview.

Evaluating. After the culture interview, group members should discuss again about their generalization of their research topic with these two questions: Do you think what you observed is something typical that often happens in the target culture? If it is not typical, is it at least possible? A presentation was given to all the classmates in class about their findings by each group.

Reflecting. Each student researcher needed to reflect about the learning process and write an individual ethnographic report. In addition, each group was required to hand in the group learning portfolio, which included their interview records, materials about discussion, and presentation.

By referring to Don Snow (2014), all of the research topics were chosen by students from Group 1 to Group 6 to compare the similarities and differences between American culture and Chinese culture and they were: gift-giving and gift-receiving; individualist and collectivist culture; compliments; food and eating; dating and marriage; and my country. In addition, the potential interview questions were designed and discussed by student group members under the teachers' guidance.

Students' intercultural ethnographic report and group learning portfolio, including the interview records, 
presentation materials were collected as data, and underwent thematic analysis for this qualitative research.

\section{Data Analysis and Findings}

The collected data, including students' intercultural ethnographic report and group learning portfolio, was undergone repeated thematic analysis. The findings (see Table 3) were organized and summarized according to the four components of Byram's (2014) ICC model. The following sections provide insights into the students' reactions to the four components. The selected quotations were most representative of the group and alphabetic letters were used to replace students' names in order to protect their privacy.

Table 3

Summary of Participants' ICC Development

\begin{tabular}{ll}
\hline Components & Students' ICC development \\
\hline \multirow{2}{*}{ Knowledge } & Acquire similarities and differences \\
& Know more about how to interact with foreigners \\
Skills & Interpreting possible explanations and relating to their own culture \\
& Know how to learn a culture and apply what have learned in real IC \\
Attitudes & Curiosity and openness \\
& Show empathy \\
Critical awareness & Critical awareness of "self” \\
\hline
\end{tabular}

\section{Knowledge}

Acquire similarities and differences. Students ware familiar with the similarities and differences between Chinese culture and Western culture for their research topic, as was stated by one student who studied the topic of gift-giving and gift-receiving in his ethnographic report:

I have never realized there were so many differences about giving gifts to Chinese and westerners. And I also knew there were similarities, maybe that was why we could communicate. For example, both westerners and Chinese use gifts to establish and maintain good relationship. (Student A)

Know more about how to interact with foreigners. From students' ethnographic report, they also revealed that they acquired more about how to interact with foreigners appropriately, which could be seen in this report:

In the past, when my foreign friend complimented about my dress, I either felt very shy, smiled and kept silent or even said, "where, where” to show my modesty out of my nervousness. But now, through observation and interview, I learned that actually I could be more confident to say, "thank you” to accept it, or pass the credit on to someone else, or open up a new conversation to shift attention away. (Student B)

\section{Skills}

Interpreting possible explanations and relating to their own culture. Instead of jumping to a negative conclusion about the misunderstanding of IC, students honed to suspend their judgment and think of different possible explanations and also relate to Chinese culture, as is mentioned in one of the students' report:

Once I met an old American man, I tried to help him with his heavy backpack on the way back to a bus station, but he said no. I offered my help several times, but he still refused my help even he seemed a little bit annoyed. I was 
unhappy and thought he was rude. But after the culture interview with my informant, he told me maybe there were some cultural reasons for him to be annoyed, like self-reliance, or thinking I am trying to practice my English with him.... Wow, I have never thought about that before. Now, for every IC situation, I will think about some possible reasons for their behavior and also ask myself: What if the same case happened in China? (Student C)

Know how to learn a culture and apply what have learned in real intercultural interaction. Students obtained more methods about learning a culture through this ethnographic approach and initially embarked on applying what they have learned in their real IC, as was evident in this part of report:

Learning a culture not only happens in classroom, maybe the best way for me to learn a culture is to learn it through the media and become a sensitive observer and reflector which interests me.... From interview with my foreign teacher, I got to know that while foreigners give gifts, they do not consider so much about the monetary value; it is the thought that counts. Therefore, for my informant's Spring Festival gift, I send him a pair of English poetic couplets instead of red packets, which made him happy. (Student D)

\section{Attitudes}

Curiosity and openness. The observation and interview with the informant exposed students to different thoughts on the same thing, which arouse students' curiosity and interest in both western culture and Chinese culture, as was seen in one of this part of report:

To talk with my foreign friend on line about culture is so much fun and opens my eyes. Now, I really want to read more books, watch more movies, or maybe travel to his hometown to know more about his culture.... (Student E)

Show empathy. Students showed more empathy by putting themselves in others' shoes, as was described in this part of report:

In order to thank my informant, I treated her out for lunch in a dim sum restaurant and there were lots of delicious food there. But she did not eat much. I urged her to eat more. She said the food was delicious but she only tried a little. Instead of judging her as an unkind person, I learned to put myself in her shoes now, maybe she was on a diet or a vegetarian something, or she did not feel well at that time. I respected her choice. (Student F)

\section{Critical Awareness}

Critical awareness of "self". Students frequently discussed with their group members, sharing new cultural insights and discoveries as well as difficulties they encountered. This report revealed that many had become more sensitive to the uniqueness of Chinese culture:

Through encounter with my western informant from the internet, I find that he loved Chinese calligraphy so much and even he learned to paint pictures with different colors of ink and add Chinese poems on them. I was so proud of Chinese culture. Well, there are something we should improve, such as when I go back home for Spring Festival, my relatives always ask me some questions like do you have a girlfriend? What about your grade? Do they know something as "privacy”? (Student G)

Critical awareness of "other”. From some students' report, I could find that they also obtain the critical awareness of "other", as was described in this report:

In the past, I worshiped American culture just as some people may say, "the western moon is rounder than Chinese moon”. But through communicating with my informant from the internet, I also got to know some bad sides. Therefore, maybe in culture, we are just different, and we are not inferior or superior to each other. (Student 


\section{Conclusion}

According to participants' comments and feedback, they all think highly of this project. Through analyzing students' reflective ethnographic report, in addition to intercultural learning, students also mentioned some other benefits they have obtained through this study, such as gaining first-hand IC experience, improving language proficiency, developing interviewing and interpersonal skills, and improving their confidence. However, some students also mentioned their research was dissatisfactory due to hard access to native speakers, long distance, insufficient language skills, potential loss of face, or busy schedules. The marriage of ethnography with cultural learning invites Chinese students to reflect on their own culture and explore the target culture, which can be used as an effective and convenient way to develop student's ICC. However, due to the less rich and diverse data collection and short duration of this project, this initial study has some its limitations. This research hopefully stimulates future researchers to mine the potential of the ethnographic approach in other classes or contexts with both qualitative and quantitative data.

\section{References}

Byram, M. (2014). Teaching and assessing intercultural communicative competence. Beijing: Foreign Language Teaching and Research Press.

Don, S. (2014). Encounters with westerners: Improving skills in English and intercultural communication. Shanghai: Shanghai Foreign Language Education Press.

Du, W. H. (2008). An examination of the ethnographic interview approach in a Chinese as a foreign language classroom. Retrieved from https://search.proquest.com/docview/304451993

$\mathrm{Fu}, \mathrm{Q}$. L. (2017). An empirical study on the effectiveness of the internet-mediated ethnography (IME) on developing intercultural communication competence (ICC). retrieved from

http://kreader.cnki.net/Kreader/CatalogViewPage.aspx?dbCode=cdmd\&filename=1017286428.nh\&tablename=CMFD20180 1 \&compose $=$ \&first $=1$ \&uid $=$

Holmes, P., \& O’Neil, G. (2012). Developing and evaluating intercultural competence: Ethnographies of intercultural encounters. International Journal of Intercultural Relations, 36(5), 708-718.

Jane, J. (2006). Ethnographic preparation for short-term study and residence in the target culture. International Journal of Intercultural Relations, 30(1), 77-98.

Lu, M. H. (2012). Using the learners as ethnographers approach to enhance intercultural learning among American college students learning Chinese as a foreign language. Retrieved from https://search.proquest.com/docview/1038368174

Robinson-Stuart, G., \& Nocon, H. (1996). Second culture acquisition: Ethnography in the foreign language classroom. The Modern Language Journal, 80(4), 431-449.

Zhang, H. L (2007). Intercultural approach to foreign language teaching. Shanghai: Shanghai Foreign Language Education Press.

Zhao, Y. Q., \& Kan, Z. J. (2016). Application of cultural clusters in global citizenship education in foreign language education. Beijing: Higher Education Press. 